\title{
Detection of JC virus DNA in peripheral blood cell subpopulations of HIV-1-infected individuals
}

\author{
Igor J Koralnik*,1,2, Jörn E Schmitz ${ }^{2}$, Michelle A Lifton², Meryl A Forman ${ }^{3}$ and Norman L Letvin ${ }^{2}$ \\ ${ }^{1}$ Department of Neurology, Beth Israel Deaconess Medical Center, Harvard Medical School, Boston, Massachusetts \\ 02215, USA; ${ }^{2}$ Division of Viral Pathogenesis, Beth Israel Deaconess Medical Center, Harvard Medical School, Boston, \\ Massachusetts 02215, USA; ${ }^{3}$ Beckman Coulter, Inc., Miami, Florida 33116, USA
}

\begin{abstract}
While it has been suggested that JC virus (JCV) migrates in B-lymphocytes from the kidney to the central nervous system where it initiates demyelination, this phase of JCV pathogenesis has not been systematically explored. To determine the peripheral blood cell subpopulation(s) infected with JCV, monocytes, granulocytes, and T and B lymphocytes from HIV-1-infected individuals and uninfected controls were purified by flow cytometry. JCV DNA could be detected by PCR amplification in all of these cell subpopulations. This finding suggests that JCV lacks specificity in its interaction with leukocytes.
\end{abstract}

Keywords: JC virus; progressive multifocal leukoencephalopathy; HIV; peripheral blood mononuclear cells; cell sorting; polymerase chain reaction

The mechanism by which JC virus (JCV) induces the demyelinating disease progressive multifocal leukoencephalopathy (PML) in immunosuppressed individuals remains unclear. Asymptomatic JCV infection occurs in $70-90 \%$ of normal persons (Walker and Padgett, 1983). JCV remains latent in the kidney, and is intermittently shed in the urine (Arthur et al, 1989; Kitamura et al, 1990; Markowitz et al, 1993; Koralnik et al, 1999). In the setting of immunosuppression, JCV can be detected in peripheral blood mononuclear cells (PBMC) and plasma (Tornatore et al, 1992; Azzi et al, 1996; Dubois et al, 1996, 1997; Ferrante et al, 1997; Koralnik et al, 1999). It has been suggested that JCV may enter the central nervous system (CNS) in infected peripheral blood cells (Major et al, 1992; Gallia et al, 1997).

JCV has been detected in two individuals with PML in bone marrow lymphocytes bearing kappa light chains (Houff et al, 1988), in one in CD45R positive cells in the brain (Major et al, 1990) and in another in peripheral blood B-lymphocytes (Monaco et al, 1996). Between 1 and $5.9 \%$ of cells from transformed B-lymphocyte lines (Atwood et al, 1992), hematopoietic progenitor cell lines and

*Correspondence: IJ Koralnik, Department of Neurology, Beth Israel Deaconess Medical Center, RE-120, 330 Brookline Avenue, Boston, Massachusetts 02215, USA

Received 4 December 1998; revised 5 January 1999; accepted 29 January 1999 primary tonsilar B-lymphocytes have been infected in vitro with JCV (Monaco et al, 1996). This virus has also been detected in B-lymphocyte-depleted peripheral blood leukocytes of HIV-infected individuals (Dubois et al, 1997) and in brain macrophages of patients with PML (Orenstein et al, 1988; Stoner et al, 1986; Boldorini et al, 1993). Finally, JCV has been found in cell-free plasma of immunosuppressed individuals (Dubois et al, 1997, 1998; Koralnik et al, 1999). These disparate observations do not provide a coherent picture of how JCV might be transported from the kidney into the CNS to initiate demyelinating disease. To clarify the mechanisms of JCV latency and spread, we have characterized the peripheral blood cells that harbor JCV in HIV-1-infected individuals.

JCV detection after double gradient separation of $P B M C$ and granulocytes

EDTA-anticoagulated peripheral blood from HIV-1infected individuals and uninfected control subjects was diluted 1:1 in PBS, and centrifuged for $30 \mathrm{~min}$ at $700 \times \mathrm{g}$ on a double gradient column consisting of a layer of Histopaque and a layer of Ficoll-diatrizoate. PBMC and granulocytes were recovered at the plasma/Ficoll interface and the Histopaque/Ficoll interface, respectively. Remaining red blood cells were eliminated by incubation in erythrocyte lysis buffer for $3 \mathrm{~min}$. The purity of the PBMC and granulocyte populations were determined by flow cytometry (Figure 1). 
DNA was extracted from these cell populations and from plasma samples as previously described (Koralnik et al, 1999). In brief, cells were lysed by addition of SDS in the presence of proteinase $\mathrm{K}$. DNA was extracted with phenol/chloroform/isoamyl alcohol and precipitated with ethanol. Plasma samples were centrifugated twice at 2000 r.p.m. for $5 \mathrm{~min}$ and filtered through $0.45 \mu$ filters to remove remaining cells. Viral particles were pelleted by centrifugation at $214000 \times \mathrm{g}$, and DNA was extracted as described above.

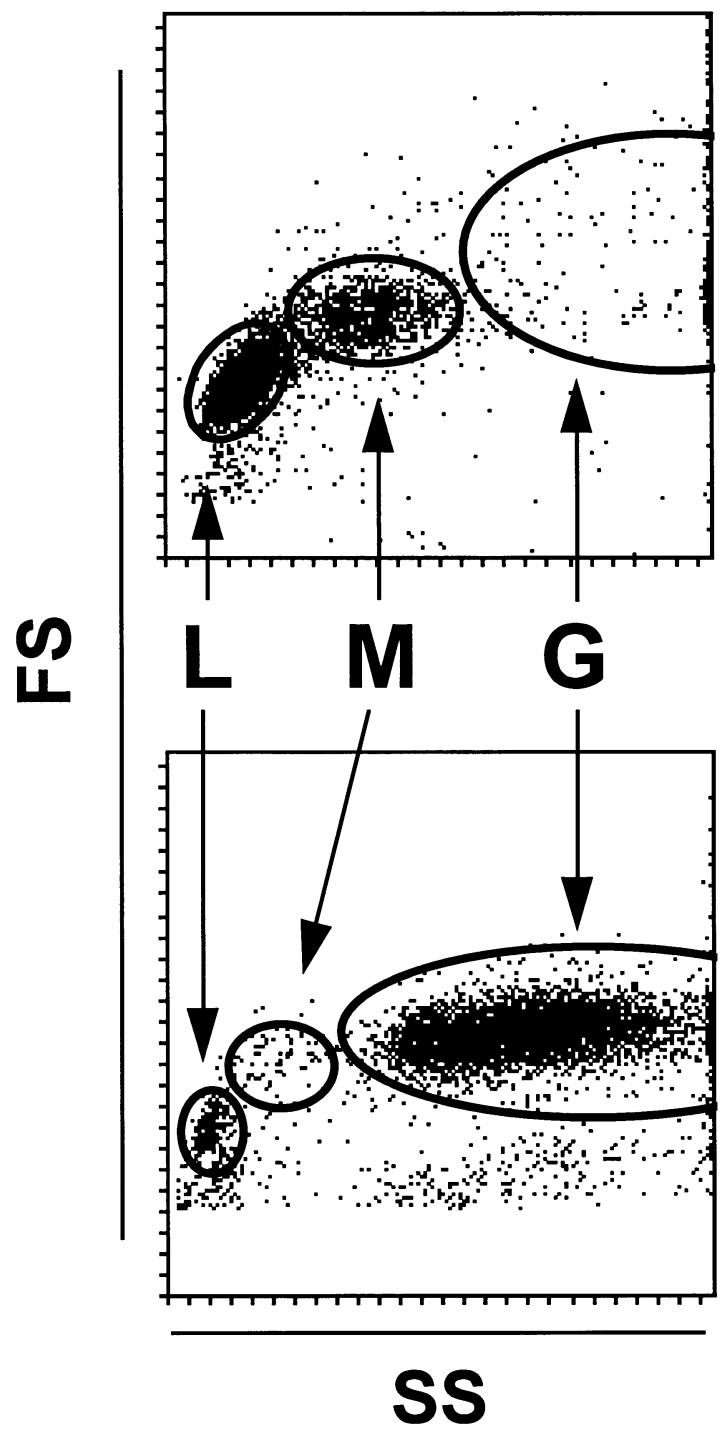

Figure 1 Flow cytometric analyses after double gradient separation of peripheral blood leukocytes from an HIV-1 seropositive patient into lymphocyte/monocyte (top panel) and granulocyte (bottom panel) enriched fractions. The enrichment of the lymphocyte/monocyte and granulocyte fractions were 92.5 and $87 \%$, respectively. For these analyses of leukocyte subsets, photomultiplier voltages were set differently in the top and bottom panel. FS: forward scatter. SS: side scatter. L: lymphocytes. M: monocytes. G: granulocytes.
PCR amplification of JCV DNA and detection of the amplified products was performed as previously described (Koralnik et al, 1999) using the primer pair VP11/VP12 which flanks a $181 \mathrm{bp}$ fragment of the VP1 gene (Gibson et al, 1993). The PCR oligonucleotide primer sequences employed are: VP11: 5'-cagatacatttgaaagtgac-3' (nt 1662-1681); VP12: 5'-ccattagagtgcacattcatc-3' (nt 1842-1822).

The amplification was carried out using 40 reaction cycles. $0.5-1.0 \mu \mathrm{g}$ of PBMC or granulocytes DNA, or DNA extracted from $6 \mathrm{ml}$ of plasma were used in a $50 \mu \mathrm{l}$ reaction consisting of $10 \mathrm{mM}$ Tris- $\mathrm{HCl}, 50 \mathrm{mM} \mathrm{KCl}, 1.5 \mathrm{mM} \mathrm{MgCl}_{2}$, $200 \mu \mathrm{M}$ of each dNTP, $2.5 \mathrm{U}$ Amplitaq DNA polymerase (Perkin Elmer, Cetus), and $25 \mathrm{pmol}$ of each oligonucleotide primer pair. Twenty five $\mu \mathrm{l}$ of the PCR reaction was analyzed by electrophoresis on a $2 \%$ agarose gel, transferred onto nylon membranes by Southern blotting, and amplified products were detected by hybridization to the JCV specific ${ }^{32} \mathrm{P}$ end-labelled oligonucleotide probe IKVP1S. The IKVP1S oligonucleotide probe sequence employed is: 5'ggacatgcttccttgttacagtgtg- $3^{\prime}$ (nt 1693-1717). A positive control JCV VP1 gene fragment was generated as previously described (Koralnik et al, 1999). Using these conditions, we could reliably detect as few as ten copies of JCV DNA.

Samples were evaluated from 48 individuals, including $5 \mathrm{HIV}+/ \mathrm{PML}+$ cases, $25 \mathrm{HIV}+/ \mathrm{PML}-$ cases, $2 \mathrm{HIV}-/ \mathrm{PML}+$ cases, $2 \mathrm{HIV}-/ \mathrm{PML}-\mathrm{im}-$ munosuppressed cases, and 14 HIV-/PML - normal control subjects. Among these, only three $\mathrm{HIV}+/ \mathrm{PML}+$ patients and $5 \mathrm{HIV}+/ \mathrm{PML}-$ patients had detectable JCV DNA in PBMC or granulocytes. The enrichment of the PBMC and granulocyte populations was $75-99 \%$ (average $87 \%$ ) (Table 1).

As shown in Table 1, JCV DNA could be detected in 6/8 PBMC and 3/8 granulocyte cell populations. Plasma samples were positive for JCV DNA in $3 / 6$ cases tested. Only one individual was positive for JCV DNA in both PBMC and granulocytes. This patient had PML, and had detectable JCV DNA in the plasma as well. These results indicate that JCV can be associated with either the PBMC or the granulocyte cell population in HIV-infected individuals.

\section{JCV detection in sorted peripheral blood cell subpopulations}

To characterize further the cells carrying JCV in the blood, T lymphocyte, B lymphocyte, monocyte and granulocyte cell populations were isolated by flow cytometric sorting. Samples were evaluated from HIV-1 seropositive subjects who had PML (four cases), or advanced AIDS with CD4 counts of less than $250 / \mu \mathrm{l}$ (six cases), and uninfected control subjects (three cases). These individuals were different from those reported in Table 1, except for case three. After double gradient centrifugation, the 
lymphocyte/monocyte and the granulocyte-enriched fractions were incubated with the following monoclonal antibodies (mAb): anti-CD3(UCHT1)APC, anti-CD19(B4)-FITC, anti-CD14(MY4)-PE, anti-CD14(Mo2)-PE, anti-CD16(3G8)-PE, (Beckman Coulter, Inc.) and anti-CD16(Leu11c)-PE (Becton Dickinson, San Jose, CA, USA). Cells were gated according to their light scatter characteristics and cell subpopulations were sorted by flow cytometry according to the positive expression of CD19 (B lymphocytes), CD3 ( $\mathrm{T}$ cells), CD14 $4^{\text {bright+ }}$ and CD16 ${ }^{\text {bright+ }}$ (monocytes), and CD14 $4^{\text {intermediate }}$ and CD16 ${ }^{\text {intermediate+ }}$ (granulocytes). The combination of two different mAb directed against CD14 and CD16 was used to include all subsets of monocytes (Thieblemont et al, 1995). Figure 2 shows an example of the degree of enrichment of blood cell populations that could be achieved using specimens obtained from both HIV-1-infected and uninfected control subjects.

As shown in Figure 2, the enrichment of blood cell subpopulations was more successful in specimens from HIV-control subjects $(98.2-99.9 \%)$ than in specimens from HIV+ individuals (91.4-99.9\%). The less efficient cell purification from specimens obtained from HIV-infected individuals may be attributable to the fragility of these activated cells in individuals with end stage AIDS. This fragility may lead to increased cell clumping. DNA from enriched cell subpopulations was extracted and PCR amplification of JCV DNA was performed as described above. The results of the JCV PCR amplifications on DNA specimens obtained from ten HIV+ and three HIV - control subjects are shown in Table 2.

JCV DNA was detected in 2/13 T-lymphocyte, 2/ 13 B-lymphocyte, 1/8 granulocyte and 2/12 mono- cyte enriched cell fractions of peripheral blood (Figure 3). It was also detected in 2/12 plasma samples (Figure 3).

In HIV-1-seronegative control subjects, JCV DNA was detected only in the $\mathrm{B}$ cell fraction of one individual (case 11). One HIV+ individual (case 7) had detectable JCV DNA only in the plasma. JCV DNA could not be detected in the unsorted or sorted cell populations of one HIV+/PML+ patient (case 4), four HIV+/PML - patients (cases 7-10) and two uninfected control subjects (cases 12 and 13). No association was observed between the cell populations that were positive for JCV DNA and the diagnosis of PML in this group of HIV+ patients.

At least one cell population in the blood specimens from three of four HIV-infected patients with PML yielded a positive PCR signal for JCV DNA. These positive PCR signals were detected in specimens from two of three HIV+/PML - individuals with CD4 counts between eight and 71/ $\mu$ l, 0/3 HIV+ individuals with CD4 counts between 168 and 223/ $\mu \mathrm{l}$, and 1/3 HIV negative control subjects. These findings are consistent with the observation that the frequency of detection of JCV in the blood increases in the setting of advanced immunosuppression (Koralnik et al, 1999).

Interestingly, unsorted PBMC or granulocyte populations from three HIV+ and one HIVindividual were PCR negative for JCV DNA while $\mathrm{T}$ cells (cases 3 and 6), monocytes (case 5), granulocytes (case 6) and B cells (case 11) enriched from the same cell populations had detectable JCV DNA. Case 3 is the only patient shown in Table 2 who had been evaluated 22 months previously for the presence of JCV DNA in the PBMC and granulocytes using the double gradient separation technique (case 3, Table 1). At that time, this HIV+l

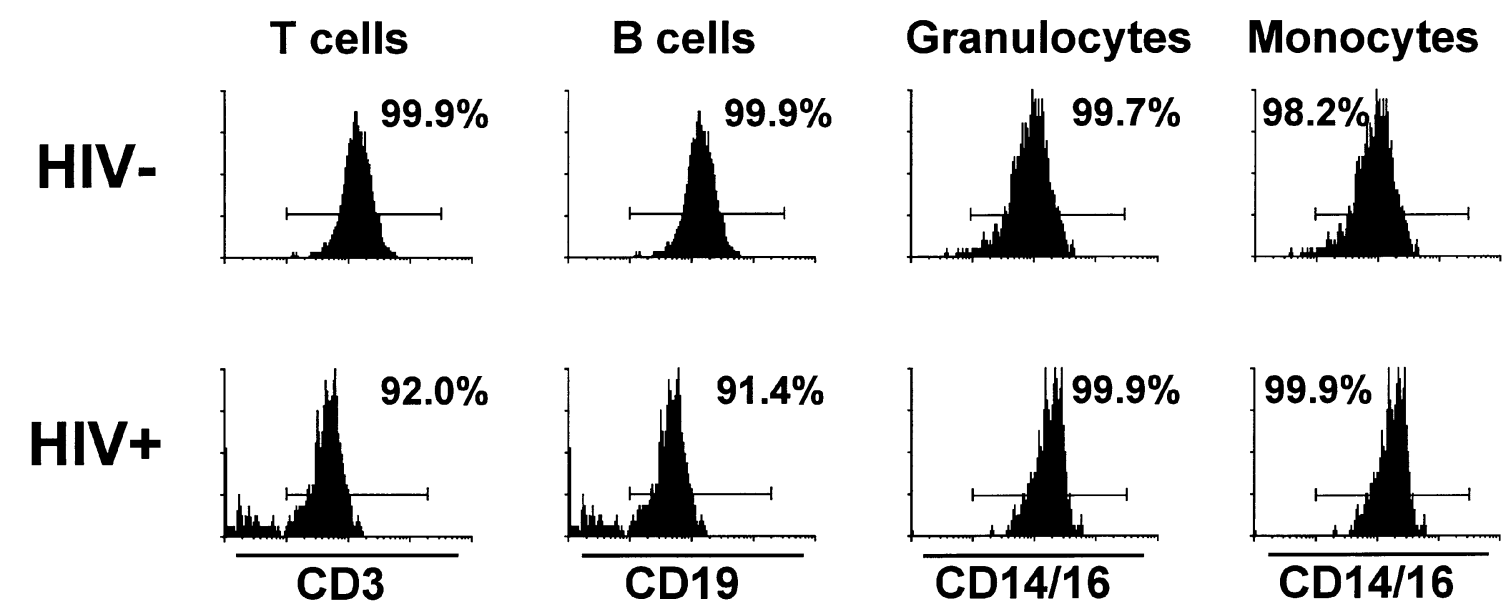

Figure 2 Flow cytometric enrichment of $\mathrm{T}$ and B cells, granulocytes and monocytes from the peripheral blood of an HIV-1seronegative (top panel) and HIV-1-seropositive individual (bottom panel). The percentages indicating the degree of cell enrichment are indicated in each panel. 
PML+ patient was PCR positive for JCV in the PBMC. His brain lesions and his neurological impairment had already improved on highly active antiretroviral therapy (HAART) when the cell sorting analyses were performed on his PBMC and granulocytes. Only his purified $\mathrm{T}$ cell fraction was positive for JCV DNA (Table 2, Figure 3).

These findings suggest that cell-associated JCV may be present in limiting amounts in the peripheral blood of these individuals, and that enrichment of specific cell populations carrying the virus is necessary to reach the threshold of detection of the PCR-based assay. This explanation is consistent with our recent finding that JCV DNA is detected in PBMC in limited amounts using quantitative PCR, between 10 and 90 copies/ $\mu$ g PBMC DNA (Koralnik et al, 1999).

Table 1 PCR detection of JCV DNA in the lymphocytes/ monocytes, granulocytes and plasma of HIV-1-infected patients, with or without Progressive Multifocal Leukoencephalopathy (PML)

\begin{tabular}{lcccc}
\hline Patients & $\begin{array}{c}\text { CD4+ } \\
\text { cells/ } \mu \mathrm{l}\end{array}$ & $\begin{array}{c}\text { Lympho/ } \\
\text { monocytes }\end{array}$ & $\begin{array}{c}\text { Granulo- } \\
\text { cytes }\end{array}$ & Plasma \\
\hline 1 HIV+/PML & 93 & $+^{\mathrm{a}}$ & + & + \\
2 HIV+/PML & 41 & + & - & + \\
3 HIV+/PML & 84 & + & - & - \\
4 HIV+ & 38 & - & + & $\mathrm{NA}^{\mathrm{b}}$ \\
5 HIV+ & 135 & - & + & - \\
6 HIV+ & 20 & + & - & - \\
7 HIV+ & 72 & + & - & $\mathrm{NA}$ \\
8 HIV+ & 421 & + & - & + \\
Total & & $6 / 8$ & $3 / 8$ & $3 / 6$ \\
\hline
\end{tabular}

${ }_{+}+$: positive detection of JCV VP1 gene DNA after PCR amplification, Southern blot and hybridization with a ${ }^{32} \mathrm{P}$ labeled JCV-specific probe as indicated in the text. ${ }^{\mathrm{b}} \mathrm{NA}$ : specimen not available.

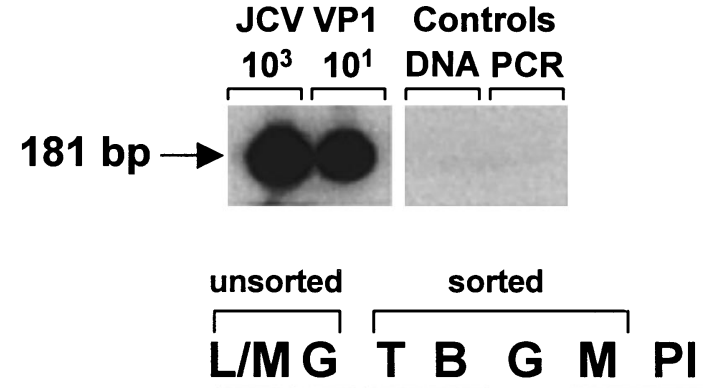

1) HIV+/PML

2) HIV+/PML

3) HIV+/PML

5) HIV+

6) HIV+

11) HIV-
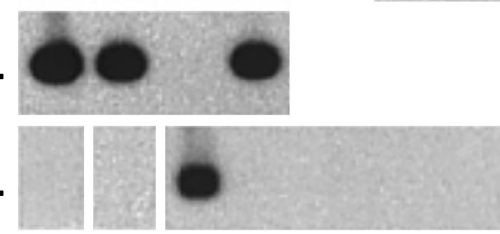
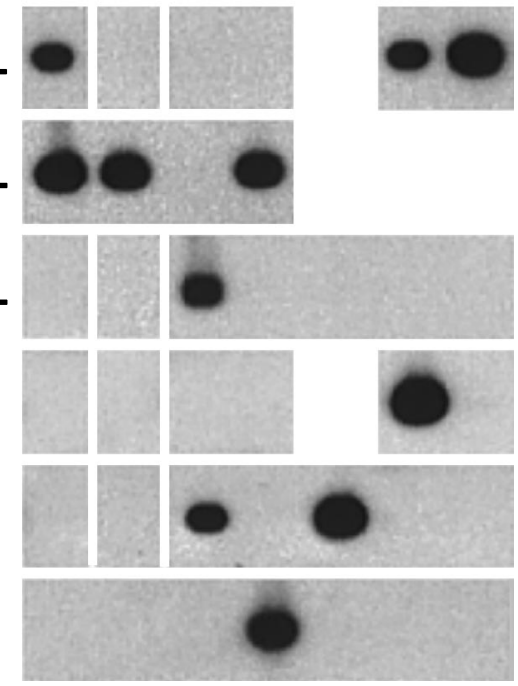

Figure 3 Detection of JCV PCR-amplified products from peripheral blood cell subpopulations by Southern blot and hybridization with the JCV-specific ${ }^{32} \mathrm{P}$-labeled probe IKVP1S. Only cases from Table 2 with positive results are shown. L/M: lymphocytes/monocytes; G: granulocytes; T: T-lymphocytes; B: B-lymphocytes; M: monocytes; Pl: plasma. The positive controls consisted of $10^{3}$ and $10^{1}$ copies of the JCV VP1 gene fragment. The negative controls consisted of JCV negative human genomic DNA and a PCR reaction control without template DNA.

Table 2 PCR detection of JCV DNA in peripheral blood cell subpopulations sorted by flow cytometry

\begin{tabular}{|c|c|c|c|c|c|c|c|c|}
\hline \multirow[b]{2}{*}{ Patients } & \multirow{3}{*}{$\frac{\text { CD } 4+\text { cells } / \mu l}{43}$} & \multicolumn{2}{|c|}{$\begin{array}{l}\text { Unsorted } \\
\text { Lympho/ }\end{array}$} & \multirow[b]{2}{*}{ T-cells } & \multicolumn{2}{|c|}{ Sorted } & \multirow[b]{2}{*}{ Monocytes } & \multirow[b]{2}{*}{ Plasma } \\
\hline & & monocytes & Granulocytes & & $B$ cells & Granulocytes & & \\
\hline $1 \mathrm{HIV}+/ \mathrm{PML}^{\mathrm{a}}$ & & $+t^{\mathrm{b}}$ & - & - & - & $\mathrm{ND}^{\mathrm{c}}$ & + & + \\
\hline $2 \mathrm{HIV}+/ \mathrm{PML}$ & 11 & + & + & - & + & $\mathrm{ND}^{\mathrm{d}}$ & $\mathrm{ND}^{\mathrm{d}}$ & $\mathrm{NA}^{\mathrm{e}}$ \\
\hline $3 \quad$ HIV+/PML & 76 & - & - & + & - & - & - & - \\
\hline 4 HIV+/PML & 6 & - & - & - & - & - & - & - \\
\hline $5 \quad \mathrm{HIV}+$ & 8 & - & - & - & - & $\mathrm{ND}^{\mathrm{c}}$ & + & - \\
\hline $6 \mathrm{HIV}+$ & 17 & - & - & + & - & + & - & - \\
\hline 7 HIV+ & 200 & - & - & - & - & $N D^{f}$ & - & + \\
\hline $8 \mathrm{HIV+}$ & 71 & - & - & - & - & $\mathrm{ND}^{\mathrm{c}}$ & - & - \\
\hline 9 HIV+ & 168 & - & - & - & - & - & - & - \\
\hline $10 \mathrm{HIV+}$ & 223 & - & $N D^{f}$ & - & - & - & - & - \\
\hline 11 HIV- & NA & - & - & - & + & - & - & - \\
\hline 12 HIV- & NA & - & - & - & - & - & - & - \\
\hline 13 HIV- & NA & - & - & - & - & - & - & - \\
\hline Total & & $2 / 13$ & $1 / 12$ & $2 / 13$ & $2 / 13$ & $1 / 8$ & $2 / 12$ & $2 / 12$ \\
\hline
\end{tabular}

${ }^{a}$ PML: progressive multifocal leukoencephalopathy. ${ }^{b_{+}}$: positive detection of JCV VP1 gene DNA after PCR amplification, Southern blot and hybridization with a ${ }^{32} \mathrm{P}-$-labeled JCV-specific probe as indicated in the text. ${ }^{\mathrm{C}} \mathrm{ND}$ : not determined, unsorted granulocyte sample already $>92 \%$ pure; ${ }^{d} \mathrm{ND}$ : not determined; ${ }^{\mathrm{e}} \mathrm{NA}$ : not available; ${ }^{\mathrm{f}} \mathrm{ND}$ : not determined because of neutropenia. 
In the same study, we were unable to detect JCV DNA in any of 18 PBMC and 13 plasma samples from HIV - control subjects. The observation that we were able to detect JCV DNA in the purified Blymphocyte peripheral blood fraction but not in the unsorted PBMC of one HIV - control (case 11) suggests that JCV viremia may occur at very low levels in immunocompetent individuals (Dorries et $a l, 1994)$. This individual was PCR negative for JCV DNA in all blood cell subpopulations on repeat testing 1 month after the evaluation shown in Table 2 and Figure 3 (data not shown).

These data confirm and extend the results of previous studies in which JCV was detected in peripheral blood B-lymphocytes (Monaco et al, 1996), as well as in B-lymphocyte-depleted peripheral blood leukocytes of HIV-1-infected individuals (Dubois et al, 1997). The fact that JCV DNA was not found exclusively in a single peripheral blood cell type raises questions about the presumed specificity of the association between JCV and B lymphocytes. Because of the extreme sensitivity of the PCR technique and the limits in the purity of cell subpopulations that could be achieved after flow cytometric sorting, it is possible that JCV might have been detected in our sorted samples in limited numbers of contaminating cells from other leukocyte subpopulations. This is unlikely, since JCV DNA was detected in a single cell type in four instances (cases 1, 3, 5, 11), and JCV DNA was found

\section{References}

Arthur RR, Dagostin S, Shah KV (1989). Detection of BK virus and JC virus in urine and brain tissue by the polymerase chain reaction. J Clin Microbiol 27: 11741179.

Atwood WJ, Amemiya K, Traub R, Harms J, Major EO (1992). Interaction of the human polyomavirus, JCV, with human B-lymphocytes. Virology 190: 716-723.

Azzi A, DeSantis R, Ciappi S, Leoncini F, Sterrantino G, Marino N, Mazzotta F, Laszlo D, Fanci R, Bosi A (1996). Human polyomaviruses DNA detection in peripheral blood leukocytes from immunocompetent and immunocompromised individuals. J NeuroVirol 2: $411-416$.

Boldorini R, Cristina S, Vago L, Tosoni A, Guzetti S, Costanzi G (1993). Ultrastructural studies in the lytic phase of Progressive Multifocal Leukoencephalopathy in AIDS patients. Ultrastructural Pathology 17: 599609.

Dorries K, Vogel E, Gunther S, Czub S (1994). Infection of human polyomaviruses JC and BK in peripheral blood leukocytes from immunocompetent individuals. Virol 198: $59-70$.

Dubois V, Lafon ME, Ragnaud JM, et al (1996). Detection of JC virus DNA in the peripheral blood leukocytes of HIV-infected patients. AIDS 10: $353-358$. in two different cell types in two cases (cases 2 and 6). Our data, therefore, did not demonstrate a preferential association of JCV with a particular peripheral blood cell subpopulation.

The receptor for JCV on blood cells is still unknown. In fact, it is possible that the cellassociated JCV DNA detected in the present study came from viral particles sticking nonspecifically to the surface of cells, and not from productively infected blood cells. Indeed, JCV seems to be present in blood during viral latency since JCV RNA, an indicator of active viral replication, was found in the blood of only 1/72 HIV-infected individuals in a recent study (Dubois et al, 1997). JC viremia, occurring in the setting of immunosuppression, is a likely mechanism of viral spread to the CNS. However, JCV in the blood appears to be carried by a variety of leukocyte subpopulations as well as in the plasma. Further studies are needed to establish the nature of the interaction of JCV and peripheral blood leukocytes in vivo.

\section{Acknowledgements}

This work was supported by Public Health Service grant NS-01919 to I.J.K. and grant AI20729 to N.L.L. We thank Ms. Evelyn Gould for assistance in the preparation of this manuscript.

Dubois V, Dutronc H, Lafon ME, Poinsot V, Pellegrin JL, Ragnaud JM, Ferrer AM, Fleury HJA (1997). Latency and reactivation of JC virus in peripheral blood of human immunodeficiency virus type 1-infected patients. J Clin Microbiol 35: 2288-2292.

Dubois V, Moret H, Lafon ME, Buffet Janvresse C, Dussaix E, Icart J, Karaterki A, Ruffault A, Taoufik Y, Vignoli C, Ingrand D (1998). Prevalence of JC virus viraemia in HIV-infected patients with or without neurological disorders: a prospective study. I NeuroVirol 4: 539-544.

Ferrante P, Caldarelli-Stefano R, Omodeo-Zorini E, Cagni AE, Cocchi L, Suter F, Maserati R (1997). Comprehensive investigation of the presence of JC virus in AIDS patients with and without progressive multifocal leukoencephalopathy. J Med Virol 52: 235-242.

Gallia GL, Houff AH, Major EO, Khalili K (1997). Review: JC virus infection of lymphocytes-revisited. IID 176: $1603-1609$.

Gibson PE, Knowles WA, Hand JF, Brown DWG (1993). Detection of JC Virus DNA in the cerebrospinal fluid of patients with progressive multifocal leukoencephalopathy. J Med Virol 39: 278-281. 
Houff SA, Major EO, Katz D, Kufta CV, Sever JL, Pittaluga S, Roberts JR, Gitt J, Saini N, Lux W (1988). Involvement of JC virus-infected mononuclear cells from the bone marrow and spleen in the pathogenesis of progressive multifocal leukoencephalopathy. $N$ Engl J Med 318: 301-305.

Kitamura T, Aso Y, Kuniyoshi N, Hara K, Yogo Y (1990). High incidence of urinary JC virus excretion in nonimmunosuppressed older patients. J Infect Diseases 161: 1128-1133.

Koralnik IJ, Boden D, Mai VX, Lord CI, Letvin NL (1999). JC virus DNA load in patients with and without Progressive Multifocal Leukoencephalopathy. Neurology, 52: $253-260$.

Major EO, Amemiya K, Elder G, Houff SA. (1990). Glial cells of the human developing brain and B cells of the immune system share a common DNA binding factor for recognition of the regulatory sequences of the human polyomavirus. J Neurosci Res 27: 461-471.

Major EO, Amemiya K, Tornatore CS, Houff SA, Berger JR. (1992). Pathogenesis and molecular biology of progressive multifocal leukoencephalopathy, the JC virus-induced demyelinating disease of the human brain. Clin Microbiol Revs 5: 49-73.

Markowitz RB, Thompson HC, Mueller JF, Cohen JA, Dynan WS (1993). Incidence of BK virus and JC virus viruria in human immunodeficiency virus-infected and -uninfected subjects. J Infect Dis 167: 13-20.
Monaco MCG, Atwood WJ, Gravell M, Major EO. (1996). JCV infection of hematopoietic progenitor cells, primary B lymphocytes and tonsillar stromal cells: implications for viral latency. J Virol 70: 7004-7012.

Orenstein JM, Janotta F (1998). Human immunodeficiency virus and papovavirus infections in acquired immunodeficiency syndrome: an ultrastructural study of 3 cases. Hum Pathol 19: 350-361.

Stoner GL, Ryschkewitsch CF, Walker DL, Webster HD (1986). JC papovavirus large tumor (T)-antigen expression in brain tissue of acquired immune deficiency syndrome (AIDS) and non-AIDS patients with progressive multifocal leukoencephalopathy. Proc Natl Acad Sci USA 83: 2271-2275.

Thieblemont N, Weiss L, Sadeghi SM, Estcourt C, Haeffner-Cavaillon N. (1995). CD14lowCD16high: a cytokine-producing monocyte subset which expands during human immunodeficiency virus infection. Eur J Immunol 25: 3418-3424.

Tornatore C, Berger JR, Houff SA, Curfman B, Meyers K, Winfield D, Major EO (1992). Detection of JC virus DNA in peripheral lymphocytes from patients with and without progressive multifocal leukoencephalopathy. Ann Neurol 31: 454-462.

Walker DL, Padgett BL (1983). The epidemiology of human polyomaviruses. In: Polyomaviruses and human neurological disease. Sever JL and Madden D (eds). Alan R Liss, Inc: New York, pp 99-106. 